\title{
Expression of NR1 and apoptosis levels in the hippocampal cells of mice treated with MK-801
}

\author{
JUAN DING $^{1 *}$, HUI-HUI ZHOU ${ }^{1,2^{*}}$, QUAN-RUI MA ${ }^{1}$, ZHONG-YI HE $^{1}$, \\ JIANG-BO MA ${ }^{1}$, YIN-MING LIU ${ }^{1}$, YI-WEI ZHANG ${ }^{1}$, YU-QING HE ${ }^{1}$ and JUAN LIU ${ }^{1}$ \\ ${ }^{1}$ Ningxia Key Laboratory of Cerebrocranial Diseases, School of Basic Medical Sciences, \\ Ningxia Medical University, Yinchuan, Ningxia $750004 ;{ }^{2}$ Department of Ultrasound, Xijing \\ Hospital, Fourth Military Medical University, Xi'an, Shaanxi 710032, P.R. China
}

Received January 29, 2017; Accepted September 9, 2017

DOI: $10.3892 / \mathrm{mmr} .2017 .7674$

\begin{abstract}
The aim of the present study was to investigate the characteristics of $\mathrm{N}$-methyl-D-aspartate receptor $\mathrm{R} 1$ (NR1) expression and apoptosis in the nerve cells of the hippocampus in schizophrenia-like mice. C57BL/6 mice were randomly allocated to the following groups: i) Blank group; ii) MK-801 group; iii) MK-801+NMDA group, according to body weight. The NMDAR antagonist, MK-801 $(0.6 \mathrm{mg} / \mathrm{kg} / \mathrm{d})$ was intraperitoneally injected daily for 14 days to induce a schizophrenia-like phenotype mouse model, and the effect of the NMDA injection via the lateral ventricle was observed. The results demonstrated that the number of NR1 positive cells in the MK-801 group increased in the CA1 and DG regions, indicating that NMDA may reverse this change. The level of damage decreased in the MK-801 treated group when compared with the blank group in the CA3 region. The protein expression of NR1 increased however, at the mRNA expression level, NR1 was lower in the MK-801 treated group when compared to the blank group; NMDA also reversed this change. In addition, early and total apoptosis detected in the hippocampal nerve cells was significantly increased in the MK-801 group when compared with the blank group, which was reversible following treatment with NMDA. These results indicated that NMDA may regulate the expression of NR1 and suppress apoptosis in hippocampal nerve cells in schizophrenia-like mice. Thus, NR1 may be a promising therapeutic target for the treatment of schizophrenia.
\end{abstract}

Correspondence to: Professor Juan Liu, Ningxia Key Laboratory of Cerebrocranial Diseases, School of Basic Medical Sciences, Ningxia Medical University, 1160 Shengli Street, Yinchuan, Ningxia 750004, P.R. China

E-mail: ryuken0518@163.com

${ }^{*}$ Contributed equally

Key words: schizophrenia, MK-801, NMDA, NR1

\section{Introduction}

Schizophrenia is a severe psychiatric disorder with a lifetime prevalence of around $1 \%$ (1). Cognitive impairments are the core symptoms of the disease which is characterized by disturbances in sensory information processing, attention, working memory and executive functions deficits (2) which are all hippocampus-dependent functions $(3,4)$. Schizophrenia imposes a heavy financial burden and many potential safety hazards to families of sufferers and society as a whole.

Recent studies focusing on the pathogenesis and treatment of schizophrenia have made significant progress in understanding the biology underpinning the disease. The glutamatergic hypothesis of schizophrenia states that dysfunction of the glutamatergic system induces imbalance between the glutamatergic and dopaminergic systems in the central nervous system (CNS) and induces some symptoms of schizophrenia (5). N-methyl-D-aspartate receptors (NMDARs) may be a key factor in the pathogenesis of schizophrenia (6-8). NMDAR is one of the ionotropic glutamatergic receptors (5), is a tetrameric structure of seven subunits including at least one obligatory subunit, N-methyl-D-aspartate receptor R1 (NR1; it includes eight functional splice variants), and varying numbers of a family of NR2 (NR2A-D) or NR3 (NR3A-B) subunits $(9,10)$. The properties of NMDARs are both complicated and diverse owing to their complex subunit compositions. The characteristics of NMDAR include high $\mathrm{Ca}^{2+}$ permeability and $\mathrm{Mg}^{2+}$ suppression closely associated with neurogenesis, neuronal survival, synaptic plasticity and the formation of learning and memory abilities (2,4,11-13). Studies have demonstrated that schizophrenia patients show abnormal synaptic plasticity, LTP and cognitive dysfunction $(11,13-15)$. The hippocampus is involved with cognitive functions, particularly in learning and memory and so was chosen as the area of particular interest for the current study. NR1 subunits are essential components of NMDARs. NR1 is very important for understanding the distribution and functions of NMDARs (8), however, the expression and regulation of NR1 in the hippocampus of schizophrenia-like mice are not known.

To investigate these issues, our study examined the expression of the NR1 subunit in the granule cell layer CA1, CA3 
and DG region, and discussed regulation of the NR1 subunit expression by NMDA. We also characterized the expression of the NR1 subunit mRNA and protein, and levels of apoptosis in the hippocampal nerve cells of schizophrenia-like mice. In conclusion, we demonstrated that NMDA can regulate the expression of NR1 and suppress apoptosis in the hippocampal nerve cells of schizophrenia-like mice.

\section{Materials and methods}

Materials. MK-801 (3 mg/ml in $0.9 \%$ saline) and NMDA $(1.5 \mu \mathrm{g} / \mathrm{ml}$ in $0.9 \%$ saline) were purchased from Sigma-Aldrich (Merck KGaA, Darmstadt, Germany). The primary antibody of NR1 was purchased from Abcam (Cambridge, MA, USA), and $\beta$-actin antibody purchased from Nanjing KeyGen Biotech Co., Ltd. (Nanjing, China). The secondary antibody of goat anti-rabbit fluorescein isothiocyanate (FITC) was purchased from CWBIO (Beijing, China), and the HRP-conjugated goat anti-rabbit antibody purchased from ZSGB-BIO (Beijing, China). Annexin V-FITC/PI kit was purchased from Yeasen (USA). TRIzol reagent was purchased from Life Technologies (Thermo Fisher Scientific, Inc., Waltham, MA, USA). All PCR primers were synthesized by Sangon Biotech Co., Ltd. (Shanghai, China). RevertAid First Strand cDNA Synthesis kit and Maxima SYBR Green qPCR Master Mix were purchased from Thermo Fisher Scientific, Inc.

Animals. Male C57BL/6 mice (23-25 grams, at 3-month old) were used in this study and provided by the Experimental Animal Center of the Ningxia Medical University. Mice were housed in groups of five in cages with free access to food and tap water for 7 days. The animal room temperature was maintained at $23 \pm 2{ }^{\circ} \mathrm{C}$, with a $12 / 12$ dark/light cycle (lights on 7:00-19:00) and 50\% humidity. All animals were handled in accordance with the standards established by the institutional animal care and use committee of Ningxia Medical University.

Experimental groups and models. Male C57BL/6 mice were divided into 3 groups ( $\mathrm{n}=12$ in each group): A blank group, a MK-801 treated group and a MK-801+NMDA treated group. In the MK-801+NMDA treated group, mice were treated intra-peritoneally with MK-801 at dose of $0.6 \mathrm{mg} / \mathrm{kg}$ at the same time every day for 14 days (16). After 14 days, mice were anesthetized by intra-peritoneal injection of chloral hydrate and mounted on a stereotaxic frame for intra-cerebroventricular injection (mm from bregma: A -0.5, L -1.0, V-2.5) of NMDA (25 ng/ $\mu \mathrm{l}, 3 \mathrm{ul}$ ) once each mouse (17). Brains were harvested 3 days after the operation $(n=12)$. In the MK-801 group (schizophrenia-like group), saline was used instead of NMDA and all other operations were the same as intra-cerebroventricular injection groups $(n=12)$. In the blank group, an equal volume of $0.9 \%$ saline was injected instead of MK-801 and NMDA $(\mathrm{n}=12)$.

Immunofluorescence (IF) staining. Mice ( $\mathrm{n}=3$ in each group) were transcardially perfused with ice-cold $0.01 \mathrm{M}$ PBS

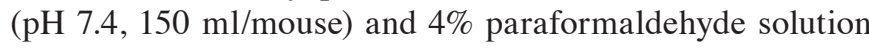
(200 ml/mouse). Brains were harvested, and post-fixed for $24 \mathrm{~h}$ in $4 \%$ paraformaldehyde, followed by immersion in $20 \%, 30 \%$ sucrose solution overnight. Brains were washed once for $10 \mathrm{~min}$ with ice cold $0.01 \mathrm{M}$ PBS, embedded in $1 \%$ gelose solution and $30 \mu \mathrm{m}$-thick coronal sections cut and used for immunofluorescent staining of NR1 in the hippocampal granule cell layer. Sections were permeabilized and blocked with blocking solution (7\% BSA and $0.3 \%$ Triton X-100 in $0.01 \mathrm{M} \mathrm{PBS}$ ) for $1 \mathrm{~h}$ at room temperature, and incubated overnight at $4^{\circ} \mathrm{C}$ with rabbit anti-NR1 (1:800). Sections were washed three times for $30 \mathrm{~min}$ with $0.01 \mathrm{M}$ PBS followed by second antibody incubation with goat anti-rabbit fluorescein isothiocyanate (FITC, 1:200) for $2 \mathrm{~h}$ at room temperature. Sections were washed three times for $30 \mathrm{~min}$ with 0.01 M PBS. Finally, the number of NR1 positive cells in granule cell layer of hippocampus was measured using confocal laser scanning microscope.

Western blotting. Mice ( $\mathrm{n}=3$ in each group) were decapitated and hippocampi were harvested. The hippocampi were put into glass homogenates with ice-cold buffer containing protease inhibitor for $45 \mathrm{~min}$. The homogenates were centrifuged at $12,000 \mathrm{x} \mathrm{g}$ for $20 \mathrm{~min}$ and the supernatant was collected (stored at $-80^{\circ} \mathrm{C}$ ). The protein levels were detected using the BCA method. Total protein in each group was separated (NR1, $\beta$-actin) by $10 \%$ sodium dodecyl sulfate-polyacrylamide gel electrophoresis (SDS-PAGE) and electrophoretically transferred onto polyvinylidene difluoride (PVDF) membranes. PVDF membranes were immersed in blocking buffer (5\% fat-free milk in PBST) for $1 \mathrm{~h}$ at room temperature and incubated overnight at $4^{\circ} \mathrm{C}$ with the primary rabbit antibodies respectively (NR1, 1:500; $\beta$-actin, 1:3,000). The membranes were then washed three times for 30 min using PBST and incubated HRP-conjugated goat anti-rabbit antibody $(1: 5,000)$ for $2 \mathrm{~h}$ at room temperature and washed three times for $30 \mathrm{~min}$ in PBST. Immuno-reactive proteins were visualized using enhanced chemiluminescence (ECL) detection and the signals were quantified by densitometry using a western blotting detection system.

Real-time PCR. Total RNA from the hippocampal tissue $(\mathrm{n}=3$ in each group) was extracted using TRIzol reagent. One microgram of the purified total RNA was reverse transcribed using a RevertAid First Strand cDNA Synthesis kit. The mRNA level of NR1 was determined using the Maxima SYBR Green qPCR Master Mix. All PCR primers were synthesized by Sangon Biotech (Shanghai, China). The forward and reverse primer sequences for NR1 were 5'-CTTCCTCCAGCCACT ACCC-3' and 5'-AGAAAGCACCCCTGAAGCAC-3', respectively; for $\beta$-actin, forward and reverse primer sequence were 5'-CCTAAGGCCAACCGTGAAAAG-3'and 5'-ACCAGA GGCATACAGGGACAAC-3', respectively. $\beta$-actin was used as an internal reference to standardize each gene. Each sample was investigated in triplicate. The relative amount of mRNA was measured using the comparative threshold $(\mathrm{Ct})$ method by normalizing target cDNA $\mathrm{Ct}$ values to that of $\beta$-actin, and the fold expression changes were calculated according to the $2^{-\Delta \Delta \mathrm{Ct}}$ method $(18,19)$.

Flow cytometry analysis. Analysis of apoptosis was performed by flow cytometry of the hippocampi $(n=3$ in each group) isolated from each mouse. Samples were digested with $0.25 \%$ trypsin at $37^{\circ} \mathrm{C}$ for $20 \mathrm{~min}$ and cell suspension were then filtered through a cell strainer (20) and the number of 

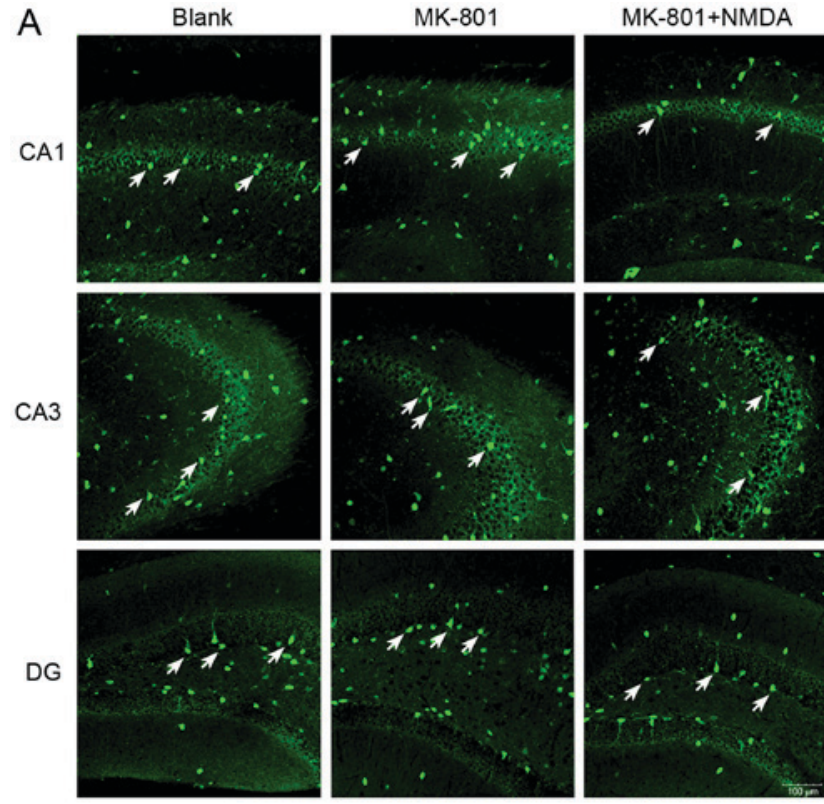

\section{B}

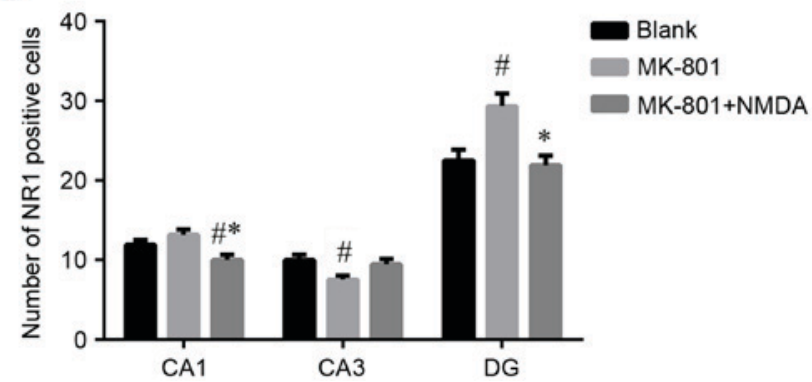

Figure 1. The NR1 positive cells distribution in different regions in hippocampus. (A) The distribution pattern of NR1 positive cells. Bars, $20 \mu \mathrm{m}$. (B) The number of NR1 positive cells. Three brain region of hippocampus: CA1, CA3, DG. Three groups: Blank, MK-801 and MK-801+NMDA. MK-801, NMDA receptor antagonist, MK-801 group (schizophrenia-like group); NMDA, N-methyl-D-aspartate; NR1, N-methyl-D-aspartate receptor $\mathrm{R} 1$. Data are presented as the mean \pm standard deviation. ${ }^{~} \mathrm{P}<0.05$ vs. blank group, ${ }^{*} \mathrm{P}<0.05$ vs. MK- 801 group. The number of NR1 positive cells in the MK-801 group increased in the CA1 $(\mathrm{P}=0.053)$ and $\mathrm{DG}(\mathrm{P}<0.001)$ regions and this change was reversible by NMDA $(\mathrm{P}<0.001, \mathrm{P}<0.001)$. The MK-801 group showed a decrease in NR1 compared with the blank group in the $\mathrm{CA} 3$ region $(\mathrm{P}<0.005)$ and again these changes were not reversible with NMDA $(\mathrm{P}=0.054)$

apoptotics cells was determined by flow cytometry assay using Annexin V-FITC/PI kit (21) and analyzed using the FACS express v2.0 software.

Statistical analysis. Data are presented as the mean \pm standard deviation. Statistical analysis was carried out in SPSS11.5 (SPSS, Inc., Chicago, IL, USA) using one-way ANOVA. $\mathrm{P}<0.05$ was considered as statistically significant.

\section{Results}

Expression of NR1 subunits in the CA1,CA3 and DG of the hippocampus. The distribution patterns of NR1 positive cells (white arrows) in the CA1, CA3 and dentate gyrus (DG) of the hippocampus are shown in Fig. 1A. The number of NR1 positive cells is shown in Fig. 1B. The results showed that the

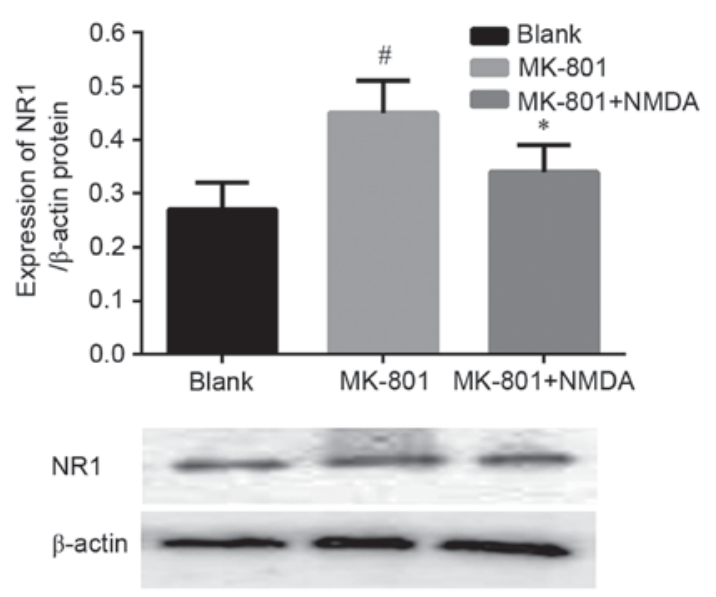

Figure 2. Expression of NR1 protein in the hippocampus of mice. Western blotting detects NR1 (105KD). NR1 levels normalized to $\beta$-actin. Three brain region of hippocampus: CA1, CA3, DG. Three groups: Blank, MK-801 and MK-801+NMDA. MK-801, NMDA receptor antagonist, MK-801 group (schizophrenia-like group); NMDA, N-methyl-D-aspartate; NR1, $\mathrm{N}$-methyl-D-aspartate receptor R1. Data are presented as the mean \pm standard deviation. ${ }^{\#} \mathrm{P}<0.05$ vs. blank group, ${ }^{*} \mathrm{P}<0.05$ vs. MK-801 group. The expression of NR1 subunit increased in the MK-801 treated group $(\mathrm{P}=0.006)$ compared with to the blank group and again this trend was reversible by NMDA $(\mathrm{P}=0.035)$.

number of NR1 positive cells in the MK-801 group increased in the CA1 $(\mathrm{P}>0.05)$ and $\mathrm{DG}(\mathrm{P}<0.05)$ regions and this change was reversible by NMDA. The MK-801 group showed a decrease in NR1 compared with the Blank group in the CA3 region $(\mathrm{P}<0.05)$.

Expression of NRI subunit protein levels in the hippocampus. Fig. 2 shows the expression of NR1 subunit protein levels in the hippocampus of experimental mice. The data showed the expression of NR1 subunit increased in the MK-801 treated group $(\mathrm{P}<0.05)$ compared with to the Blank group and again this trend was reversible by NMDA.

Expression of NR1 subunit mRNA levels in hippocampus. The mRNA levels of the NR1 subunit normalized to $\beta$-actin in hippocampus of mice are shown in Fig. 3. The data show that the mRNA expression of NR1 subunit decreased in the MK-801 treated group $(\mathrm{P}<0.05)$ compared to the Blank group. This change was reversed by NMDA although no statistical significance was detected $(\mathrm{P}>0.05)$.

Apoptosis of hippocampal nerve cells. From Fig. 4 it can be seen that the early and total levels of apoptosis in the hippocampal nerve cells significantly increased $(\mathrm{P}<0.05)$ in the MK-801 group compared to the Blank group. In contrast, these changes were reversible by NMDA $(\mathrm{P}<0.05)$. The normal live cells (NLC) are representative of the survival rate of hippocampus nerve cells. The number of NLC decreased in the MK-801 group compared to the blank group $(\mathrm{P}<0.05)$ and again these changes were reversible with NMDA.

\section{Discussion}

The prevalence of schizophrenia increased to $1.0 \%$ between 1990 and 2010 all over the world (22). The underlying 


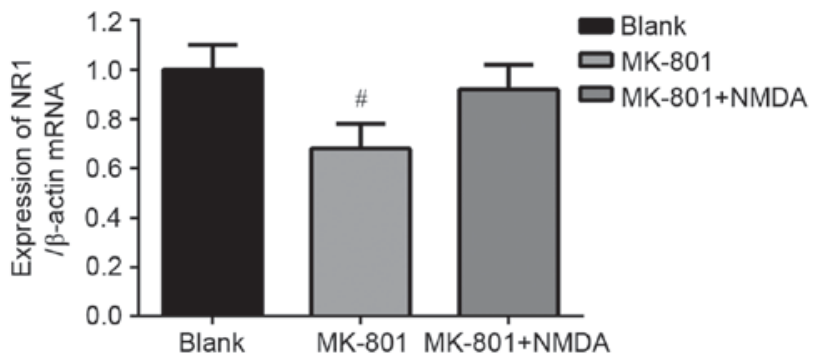

Figure 3. Expression of NR1 mRNA in the hippocampus of mice. Expression of NR1 relatives to $\beta$-actin. Three brain region of hippocampus: CA1, CA3, DG. Three groups: Blank, MK-801 and MK-801+NMDA. MK-801, NMDA receptor antagonist, MK-801 group (schizophrenia-like group); NMDA, N-methyl-D-aspartate; NR1, N-methyl-D-aspartate receptor R1. Data are presented as the mean \pm standard deviation. ${ }^{*} \mathrm{P}<0.05$ vs. blank group. The mRNA expression of NR1 subunit decreased in the MK-801 treated group $(\mathrm{P}<0.005)$ compared to the Blank group. This change was reversed by NMDA although no statistical significance was detected $(\mathrm{P}=0.057)$.

pathophysiological mechanisms of the disease are complex and remain to be fully elucidated. NMDAR is a major glutamate receptor subtype that is known to play a key role in learning and memory. NMDARs include NR1, NR2 (2A-2D), NR3 (3A-3B). NR1 subunits are the essential and obligatory components of NMDARs. NR1 subunits play an important role in determining the properties of NMDARs. Recently, NMDAR has received great attention on schizophrenia research. Dysfunction of NMDAR in the hippocampus is very important for the formation of schizophrenia (8).

We adopted an MK-801 administrated mouse model to investigate NR1 expression pattern and hippocampal neuron survival deficit in schizophrenia. MK-801 is a NMDAR antagonist per se. We worried changes released in this model may not be schizophrenia-related, but just a classical receptor-ligand feedback response of physiological process. Actually, no animal model can accurately reproduce all aspects of schizophrenia but mouse models can mimic several important aspects of the disease. MK-801 has been used for inducing a schizophrenia-like phenotype in rodents $(23,24)$ which leads to different degrees of cognitive impairment (25-27). Some studies have shown hypofunction of the NMDA receptor by chronic treatment with MK-801 (28) or cell death in the hippocampus following NMDAR hypofunction (29). NMDAR subunits are known to play an important role in determining neurotoxic (30), functional and psychiatric effects in the hippocampus $(31,32)$.

In this study, the results showed that the number of NR1 positive cells significantly increased in the hippocampal granule cell layer of the DG and CA1 regions, but decreased in
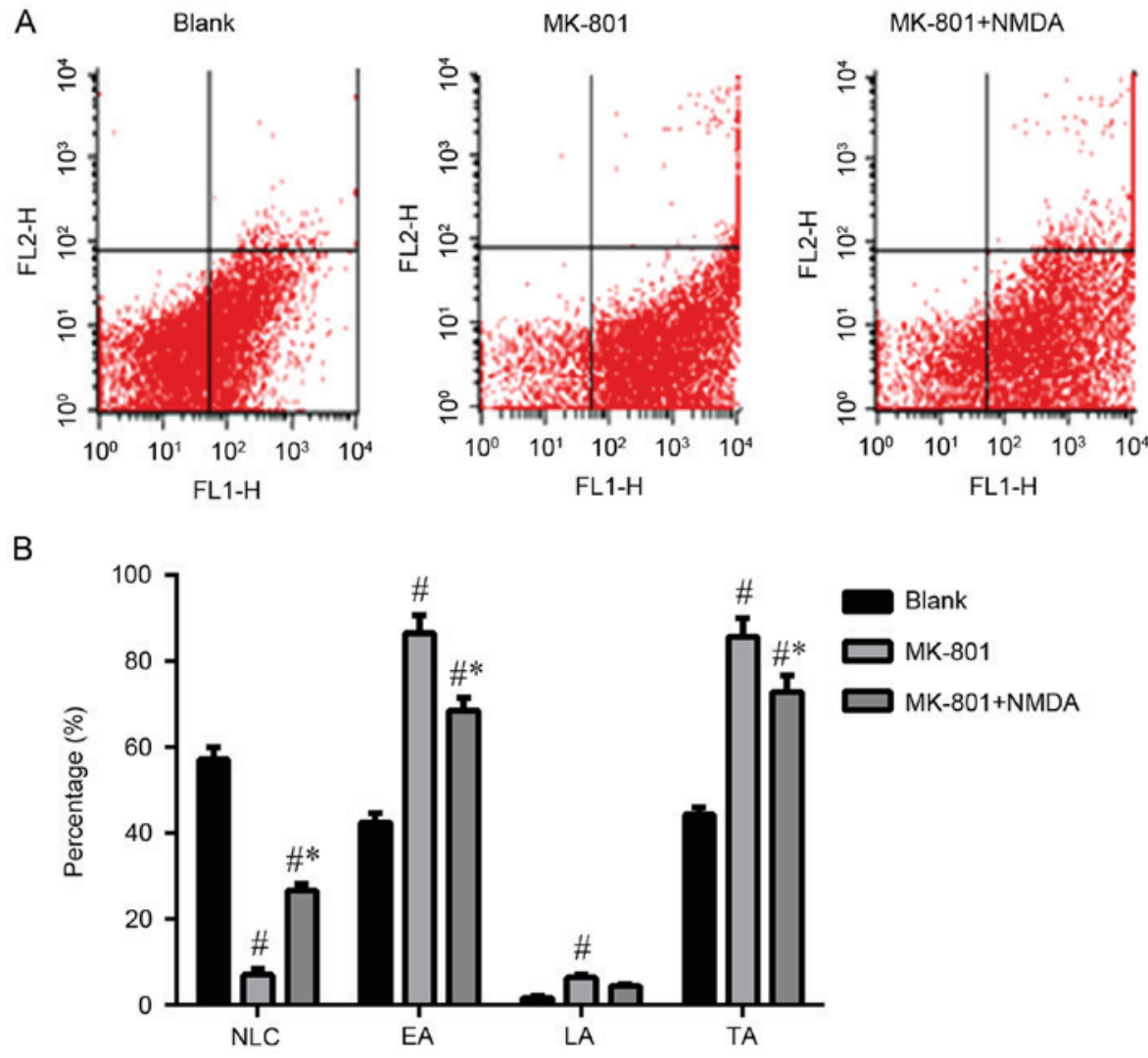

Figure 4. Apoptosis of hippocampal nerve cells. (A) Flow cytometry with apoptosis markers (FITC-Annexin V and PI). Three brain region of hippocampus: CA1, CA3, DG. Three groups: Blank, MK-801 and MK-801+NMDA. MK-801, NMDA receptor antagonist, MK-801 group (schizophrenia-like group); NMDA, N-methyl-D-aspartate; NR1, N-methyl-D-aspartate receptor R1. NLC, normal live cells; EA, early apoptosis; LA, late apoptosis; TA, total apoptosis. (B) Data are presented as the mean \pm standard deviation. ${ }^{\#} \mathrm{P}<0.05$ vs. blank group, ${ }^{*} \mathrm{P}<0.05 \mathrm{vs}$. MK-801 group. The early and total levels of apoptosis in the hippocampal nerve cells significantly increased $(\mathrm{P}<0.001, \mathrm{P}<0.001)$ in the $\mathrm{MK}-801$ group compared to the Blank group. In contrast, these changes were reversible by NMDA $(\mathrm{P}<0.001, \mathrm{P}<0.005)$. The number of NLC decreased in the MK-801 group compared to the blank group $(\mathrm{P}<0.001)$ and again these changes were reversible with NMDA $(\mathrm{P}<0.005)$. The number of LA increased in the MK-801 group compared to the blank group $(\mathrm{P}=0.046)$ and again these changes were not reversible with NMDA $(\mathrm{P}=0.308)$. 
the CA3 region of schizophrenia-like mice induced by MK- 801 . NMDA was shown to reverse these changes. The NR1 total protein levels significantly increased, whilste the mRNA levels were reduced in the hippocampus of schizophrenia-like mice induced by MK-801. NMDA could also reverse these changes. Other studies of NMDAR expression in schizophrenia have shown variable changes at the transcript and protein expression levels in different areas of the brain. For example, study have shown that the protein expression of NR1 in the anterior cingulate cortex increased (33) or was found to be unchanged in hippocampus (34). However, another study found that NR1 protein expression was reduced in the prefrontal cortex, hippocampus and hippocampal DG region (35). Furthermore, at the mRNA level, expression has been shown to be decreased in the hippocampus $(36,37)$, and the expression of the NR1 protein and mRNA levels were contradictory in the cortex of schizophrenia mice (33).

Another study examined NR1 expression in postmortem samples from patients with schizophrenia and comparison subjects. The data showed that at the transcriptional level, NR1 levels were lower in the thalamus of schizophrenia patients compared to control subjects (38). These studies support our experimental results to a certain extent. The current study has demonstrated that transcriptional changes of the NMDAR subunit expression in cortical areas appear to be associated with specific regions (33). These data may be explained by three supporting hypotheses. Firstly, the regional specificity expression of NR1 protein levels comes from the mRNA and the differential expressions in the CA1, CA3 and DG region contribute to the function of different areas (4). Secondly, it is possible that the peak of expression is not the same point at the protein and mRNA levels. Finally, NR1 may be involved in regulation of other complex components of glutamatergic pathways that are associated with schizophrenia (33).

The levels of apoptosis in the hippocampal nerve cells increased in schizophrenia-like mice induced by MK-801 which could be reversed by NMDA. Studies have shown that hyperfunction of glutamate receptors such as NMDA receptors increases intracellular $\mathrm{Ca}^{2+}$ levels. The continual influx of $\mathrm{Ca}^{2+}$ through the open NMDA receptors results in mitochondrial stress which attempts to sequester and buffer $\mathrm{Ca}^{2+}$. As mitochondrial membrane potential decreases due to the overflow of $\mathrm{Ca}^{2+}$ and mitochondria reverse their ATP synthase in an attempt to restore $\mathrm{Ca}^{2+}$ homeostasis. Eventually, the excess $\mathrm{Ca}^{2+}$ uptake causes loss of mitochondrial membrane potential, mitochondrial swelling, opening of the mitochondrial permeability transition pore $(39,40)$, outer membrane rupture and loss of $\mathrm{Ca}^{2+}$, and apoptogenic factors into the cytoplasm. This process ultimately results in neuronal cell death (38). Our experimental data show that the apoptosis of hippocampal nerve cells significantly increased in schizophrenia-like mice induced by MK- 801 and these changes could be reversed by NMDA.

We demonstrated that NR1 significantly contributes to the acquisition and apoptosis of hippocampal nerve cells in schizophrenia-like mice. NMDA can effectively regulate the expression of NR1 and levels of apoptosis in hippocampal nerve cells in schizophrenia-like mice, whereas the exactly underprinning molecular mechanisms need to be further clarified.
In summary, we have demonstrated that the expression of NR1 markedly increased in the hippocampus of schizophrenia-like mice, but showed differential trends in the CA1, CA3 and DG regions. NMDAR hyperfunction induced apoptosis in hippocampal nerve cells. NMDA contributes to positive function in schizophrenia, and may be offer an important molecular pathway for therapeutic intervention. NR1 might hold much potential as target in the therapy of schizophrenia.

\section{Acknowledgements}

This work was supported by the National Natural Science Foundation of China (nos. 81160169, 81460214, 31460255, 31660270) and the Natural Science Foundation of Ningxia (NZ14058) and West China Top Class Discipline Project in Basic Medical Sciences, Ningxia Medical University.

\section{References}

1. de Candia TR, Lee SH, Yang J, Browning BL, Gejman PV, Levinson DF, Mowry BJ, Hewitt JK, Goddard ME, O'Donovan MC, et al: Additive genetic variation in schizophrenia risk is shared by populations of African and European descent. Am J Hum Genet 93: 463-470, 2013.

2. Sánchez-Blázquez P, Rodríguez-Muñoz M and Garzón J: The cannabinoid receptor 1 associates with NMDA receptors to produce glutamatergic hypofunction: Implications in psychosis and schizophrenia. Front Pharmacol 4: 169, 2014.

3. Nakashiba T, Cushman JD, Pelkey KA, Renaudineau S, Buhl DL, McHugh TJ, Rodriguez Barrera V, Chittajallu R, Iwamoto KS, McBain CJ, et al: Young dentate granule cells mediate pattern separation, whereas old granule cells facilitate pattern completion. Cell 149: 188-201, 2012.

4. Tannenholz L, Jimenez JC and Kheirbek MA: Local and regional heterogeneity underlying hippocampal modulation of cognition and mood. Front Behav Neurosci 8: 147, 2014.

5. Gaspar PA, Bustamante ML, Silva H and Aboitiz F: Molecular mechanisms underlying glutamatergic dysfunction in schizophrenia: Therapeutic implications. J Neurochem 111: 891-900, 2009.

6. Howes OD and Murray RM: Schizophrenia: An integrated sociodevelopmental-cognitive model. Lancet 383: 1677-1687, 2014.

7. Penzes P, Cahill ME, Jones KA, VanLeeuwen JE and Woolfrey KM: Dendritic spine pathology in neuropsychiatric disorders. Nat Neurosci 14: 285-293, 2011.

8. Ju P and Cui D: The involvement of N-methyl-d-aspartate receptor (NMDAR) subunit NR1 in the pathophysiology of schizophrenia. Acta Biochim Biophys Sin (Shanghai) 48: 209-219, 2016.

9. Ghasemi M, Phillips C, Trillo L, De Miguel Z, Das D and Salehi A: The role of NMDA receptors in the pathophysiology and treatment of mood disorders. Neurosci Biobehav Rev 47: 336-358, 2014.

10. Henson MA, Roberts AC, Pérez-Otaño I and Philpot BD: Influence of the NR3A subunit on NMDA receptor functions. Prog Neurobiol 91: 23-37, 2010.

11. Hardingham GE and Bading H: Synaptic versus extrasynaptic NMDA receptor signalling: Implications for neurodegenerative disorders. Nat Rev Neurosci 11: 682-696, 2010.

12. Lau CG and Zukin RS: NMDA receptor trafficking in synaptic plasticity and neuropsychiatric disorders. Nat Rev Neurosci 8: 413-426, 2007.

13. Volianskis A, France G, Jensen MS, Bortolotto ZA, Jane DE and Collingridge GL: Long-term potentiation and the role of N-methyl-D-aspartate receptors. Brain Res 1621: 5-16, 2015.

14. Bliss TV, Collingridge GL and Morris RG: Synaptic plasticity in health and disease: Introduction and overview. Philos Trans R Soc Lond B Biol Sci 369: 20130129, 2013.

15. Soriano FX, Papadia S, Hofmann F, Hardingham NR, Bading H and Hardingham GE: Preconditioning doses of NMDA promote neuroprotection by enhancing neuronal excitability. J Neurosci 26: 4509-4518, 2006. 
16. Jones KS, Corbin JG and Huntsman MM: Neonatal NMDA receptor blockade disrupts spike timing and glutamatergic synapses in fast spiking interneurons in a NMDA receptor hypofunction model of schizophrenia. PLoS One 9: e109303, 2014.

17. Ahmad AS, Saleem S, Ahmad M and Doré S: Prostaglandin EP1 receptor contributes to excitotoxicity and focal ischemic brain damage. Toxicol Sci 89: 265-270, 2006.

18. Zapatero-Solana E, García-Giménez JL, Guerrero-Aspizua S, García M, Toll A, Baselga E, Durán-Moreno M, Markovic J, García-Verdugo JM, Conti CJ, et al: Oxidative stress and mitochondrial dysfunction in Kindler syndrome. Orphanet J Rare Dis 9: 211,2014

19. Jiao Y, Liu C, Cui FM, Xu JY, Tong J, Qi XF, Wang LL and Zhu W: Long intergenic non-coding RNA induced by X-ray irradiation regulates DNA damage response signaling in the human bronchial epithelial BEAS-2B cell line. Oncol Lett 9: 169-176, 2015.

20. Zhang Z, Zhao C, Liu B, Liang D, Qin X, Li X, Zhang R, Li C, Wang H, Sun D and Cao F: Inositol pyrophosphates mediate the effects of aging on bone marrow mesenchymal stem cells by inhibiting Akt signaling. Stem Cell Res Ther 5: 33, 2014.

21. Pervaiz $\mathrm{N}$ and Hoffman-Goetz L: Immune cell inflammatory cytokine responses differ between central and systemic compartments in response to acute exercise in mice. Exerc Immunol Rev 18: 142-157, 2012.

22. Whiteford HA, Degenhardt L, Rehm J, Baxter AJ, Ferrari AJ, Erskine HE, Charlson FJ, Norman RE, Flaxman AD Johns N, et al: Global burden of disease attributable to mental and substance use disorders: Findings from the global burden of disease study 2010. Lancet 382: 1575-1586, 2013.

23. Yu J, Qi D, Xing M, Li R, Jiang K, Peng Y and Cui D: MK-801 induces schizophrenic behaviors through downregulating Wnt signaling pathways in male mice. Brain Res 1385: 281-292, 2011.

24. Kim TW, Kang HS, Park JK, Lee SJ, Baek SB and Kim CJ: Voluntary wheel running ameliorates symptoms of MK-801-induced schizophrenia in mice. Mol Med Rep 10: 2924-2930, 2014.

25. Knott $A B$ and Bossy-Wetzel E: Nitric oxide in health and disease of the nervous system. Antioxid Redox Signal 11: 541-554, 2009.

26. Mandillo S, Rinaldi A, Oliverio A and Mele A: Repeated administration of phencyclidine, amphetamine and MK-801 selectively impairs spatial learning in mice: A possible model of psychotomimetic drug-induced cognitive deficits. Behav Pharmacol 14: 533-544, 2003

27. Mohn AR, Gainetdinov RR, Caron MG and Koller BH: Mice with reduced NMDA receptor expression display behaviors related to schizophrenia. Cell 98: 427-436, 1999.

28. Rujescu D, Bender A, Keck M, Hartmann AM, Ohl F, Raeder H, Giegling I, Genius J, McCarley RW, Möller HJ and Grunze H: A pharmacological model for psychosis based on N-methyl-D-aspartate receptor hypofunction: Molecular, cellular, functional and behavioral abnormalities. Biol Psychiatry 59: 721-729, 2006.
29. Watanabe Y, Müller MK, von Engelhardt J, Sprengel R, Seeburg PH and Monyer H: Age-dependent degeneration of mature dentate gyrus granule cells following NMDA receptor ablation. Front Mol Neurosci 8: 87, 2016.

30. Anastasio NC, Xia Y, O'Connor ZR and Johnson KM: Differential role of $\mathrm{N}$-methyl-D-aspartate receptor subunits $2 \mathrm{~A}$ and $2 \mathrm{~B}$ in mediating phencyclidine-induced perinatal neuronal apoptosis and behavioral deficits. Neuroscience 163: 1181-1191, 2009.

31. Kocsis B: Differential role of NR2A and NR2B subunits in N-methyl-D-aspartate receptor antagonist-induced aberrant cortical gamma oscillations. Biol Psychiatry 71: 987-995, 2012.

32. Inta D, Vogt MA, Luoni A, Filipović D, Lima-Ojeda JM, Pfeiffer N, Gasparini F, Riva MA and Gass P: Significant increase in anxiety during aging in mGlu5 receptor knockout mice. Behav Brain Res 241: 27-31, 2013.

33. Kristiansen LV, Huerta I, Beneyto M and Meador-Woodruff JH: NMDA receptors and schizophrenia. Curr Opin Pharmacol 7: 48-55, 2007.

34. Toro C and Deakin JF: NMDA receptor subunit NRI and postsynaptic protein PSD-95 in hippocampus and orbitofrontal cortex in schizophrenia and mood disorder. Schizophr Res 80: 323-330, 2005

35. Park JK, Lee SJ and Kim TW: Treadmill exercise enhances NMDA receptor expression in schizophrenia mice. J Exerc Rehabil 10: 15-21, 2014

36. Law AJ and Deakin JF: Asymmetrical reductions of hippocampal NMDAR1 glutamate receptor mRNA in the psychoses. Neuroreport 12: 2971-2974, 2001.

37. Gao XM, Sakai K, Roberts RC, Conley RR, Dean B and Tamminga CA: Ionotropic glutamate receptors and expression of $\mathrm{N}$-methyl-D-aspartate receptor subunits in subregions of human hippocampus: Effects of schizophrenia. Am J Psychiatry 157: $1141-1149,2000$

38. Ibrahim HM, Hogg AJ Jr, Healy DJ, Haroutunian V, Davis KL and Meador-Woodruff JH: Ionotropic glutamate receptor binding and subunit mRNA expression in thalamic nuclei in schizophrenia. Am J Psychiatry 157: 1811-1823, 2000.

39. Gono T, Kawaguchi Y, Kaneko H, Nishimura K, Hanaoka M, Kataoka S, Okamoto Y, Katsumata Y and Yamanaka H: Anti-NR2A antibody as a predictor for neuropsychiatric systemic lupus erythematosus. Rheumatology (Oxford) 50: 1578-1585, 2011.

40. Faust TW, Chang EH, Kowal C, Berlin R, Gazaryan IG, Bertini E, Zhang J, Sanchez-Guerrero J, Fragoso-Loyo HE, Volpe BT, et al: Neurotoxic lupus autoantibodies alter brain function through two distinct mechanisms. Proc Natl Acad Sci USA 107: 18569-18574, 2010 . 